\title{
Informing via Websites: Comparative Assessment of University Websites
}

\author{
Stefka Toleva-Stoimenova \\ State University of Library \\ Science and Information \\ Technologies, Sofia, Bulgaria
}

s toleva@yahoo.com

\author{
Dimitar Christozov \\ American University in \\ Bulgaria, Blagoevgrad, \\ Bulgaria
}

dgc@aubg.bg

\begin{abstract}
The paper focuses on the problems related to information systems assessment from the point of view of informing users. More specifically the paper tries to answer whether the examined information systems provide users with information in a form, format, and schedule that maximizes its effectiveness in the sense of informing science. Measures of information systems usability are used in evaluation of the ability of information systems to inform users effectively. A framework, model and assessment methodology are presented. Results of an empirical experiment conducted to evaluate informativeness of university websites are shared.
\end{abstract}

Keywords: information system, website, evaluation, effectiveness, quality of informing.

\section{Introduction}

The rise of information and communication technologies and rapid growth of the volume of accessible information have a huge impact on society. On the other hand, information systems progress follow in the train of evolution of languages, culture, behavior and growing information needs in the modern society. They play a crucial role in the mediation between information resources and the users of information.

Usability is the term describing the performance of Information Systems nowadays. It is not dependent only on technological characteristics of the information system, which are very important, but also on the quality of information provided, measured by satisfaction of users' needs, and psychological and behavioral aspects of the human cognitive process in acquiring information and learning.

Usability refers to the quality of a system and the process of designing a usable system. Because of the complexity of information systems and the variety of ways information systems are used, the

Material published as part of this publication, either on-line or in print, is copyrighted by the Informing Science Institute. Permission to make digital or paper copy of part or all of these works for personal or classroom use is granted without fee provided that the copies are not made or distributed for profit or commercial advantage AND that copies 1) bear this notice in full and 2) give the full citation on the first page. It is permissible to abstract these works so long as credit is given. To copy in all other cases or to republish or to post on a server or to redistribute to lists requires specific permission and payment of a fee. Contact Publisher@InformingScience.org to request redistribution permission. usability represents a multi-dimensional property.

ISO definition is usage, user and contextually oriented: "the extent to which a product can be used by specified users to achieve specified goals with effectiveness, efficiency and satisfaction in a specified context of use." ( ISO 9241)

The term effectiveness relates to taskcompletion rates. It depends on the ac- 
curacy and completeness with which users solve certain tasks and sub-tasks. Indicators of effectiveness include quality of solution and error rates.

Efficiency can be described as the speed in which users can complete their tasks accurately. ISO 9241 defines efficiency as the total resources consumed in performing tasks. Consequently, indicators of efficiency include task completion time and learning time.

Satisfaction comprises user's comfort and attitudes towards the use of the system. It depends on whether a task is solved accurately and completely or not; and whether the process of solving the task was enjoyable or frustrating. Sometimes measures of satisfaction can provide a useful indication of the user's perception of system usability, even if it is not possible to obtain measures of effectiveness and efficiency.

Besides, the characteristics of the context in which an information system is used may be as important in determining usability as the characteristics of the information system itself. The overall system consists of users, with their tasks, equipment (hardware, software and materials) and physical and organizational environments which influence the interaction between the user and information system (Bevan \& Macleod, 1994; Frøkjær \& Hertzum, 2000).

In this paper we share the experience obtained in assessment of university websites, considering them as information systems. This inquiry continues the development of a theoretical model of websites evaluation as proposed by Toleva-Stoimenova (see Toleva-Stoimenova, 2010).

The paper is organized in two sections:

The first section represents a framework of assessing websites' usability in respect to its effectiveness, efficiency, and user satisfaction. Those three criteria and the relevant quantitative and qualitative measures, divided into three groups: measures for quality of retrieved information, technology-oriented measures, user-oriented measures, are considered. The framework is constructed as a methodology for website evaluation based on a matrix model. The model represents the relations between criteria and measures.

The second section is dedicated to an empirical experiment for evaluation of university websites as illustration of the application of the methodology in practice. Data collected in this empirical experiment are analysed and discussed.

In the conclusion we summarize the lessons learned during the assessment of University websites' usability in respect to applicability of the proposed model. We also provide directions for our further research.

\section{Information Systems Evaluation Framework}

\section{Website Evaluation Criteria}

How to evaluate information systems has been an important research issue in the relevant literature. There are many approaches, models, indicators and measures explored for evaluating information systems and their specific aspects, components or properties.

DeLone and McLean's comprehensive framework considers six constructs, which provides a generic research infrastructure for corporate information systems assessment (DeLone and McLean, 1992). Considering DeLone and McLean's model, Sabherwal, Jeyaraj and Chowa provided an information systems theoretical model based on three constructs, namely: context-related, userrelated and information systems' success related (Sabherwal, Jeyaraj and Chowa, 2006). DeLone and McLean's model has been discussed, revised and extended in the literature over the years by many authors (see Pitt et al.,1995; Seddon, 1997; Jiang et al., 2002 and Gable, Darshana and Chan, 2003 (to mention a few). 
Nielsen associates five attributes to usability: easy to learn (learnability), efficient to use (efficiency), easy to remember (memorability), the relevance of prevention of catastrophic errors for applications such as process control or medical applications (few errors), and pleasant to use (satisfaction). (Nielsen, 1993)

Some authors consider user satisfaction as one of the most important measures of Information Systems' success. There have been many publications devoted to establishing standard user satisfaction instruments since the 1980s (Ives et al. 1983; Baroudi et al. 1986; Doll and Torkzadeh, 1988), when data computing in organizations moved from stressing on data processing optimization to emphasizing the end-user computing.

Introduction and rapid advances of the Internet forced many information systems to turn into web-based information systems, enabling access through multiple channels in a dynamic and competitive environment. On the Web, usability of particular information system is a significant factor. As the amount of available digital information grows, especially on the World Wide Web, the skills to search and navigate become critically important. The common users want to accomplish a specific task as timely, accurately and completely as possible, and the interaction experience of doing so to be as pleasurable as possible with minimal user frustration.

The Doll and Torkzadeh proposed a scale that has been used later to measure user satisfaction of web-based information systems (Doll and Torkzadeh, 1988). They proposed a 12-item model providing five determinants framework of user satisfaction: content, accuracy, format, ease of use and timeliness. It helps to obtain the users' perceptions and expectations for a specific service's characteristics. A preliminary study has attempted to incorporate web usability principles: personalisation, structure, navigation, layout, search and performance (see Zviran et al., 2006)

The main goal of the current study is the evaluation of the quality of informing via a web-based information system, the website in particular. Websites are not typical information retrieval systems. There are a number of differences which distinguish (ed) those two categories of information systems. The Internet contains an immense amount and variety of information that is posted by individuals and organisations from around the world, providing freedom to both parties - publishers and users. It may be a gateway to a set of structured databases, textual databases, or other services outside of the Web itself. On the other hand, a classical retrieval information system provides a well structured access to data organized in a way to satisfy particular predefined users' needs.

The most typical feature of websites, in comparison with traditional information systems, is their target audience. It is very heterogeneous and users have different ability to operate on the websites. Websites' functionality requires a certain level of competence. Also, there is no single body or organisation that ensures the quality of information published in Internet. Users need to acquire skills for critical evaluation of provided information, which will enable them to identify and extract trustworthy information that meets their needs. It is not enough to make a given site usable, it is important to assess how a particular user interacts with the site. From the developer's perspective, achieving usability is important because it makes the difference between the success or failure of the website. That is why, nowadays, there is a shift in development attitude from designing for users to designing with users. User-oriented website design is the way to meet users' needs by including users as an integral part in the design and development process. Consequently web design focuses on usability issues and design of user interface in a way to satisfy the variety of searching and navigating behaviors. The term "intuitive interface" describes the modern view on websites' design. Furthermore the current state of information technologies is good enough and technology related issues are not a major concern nowadays.

The new dynamic environment has generated the necessity to look into the task of information systems assessment through a new perspective. Application of traditional assessment methods to 
web domain is not more suitable or does not addresses all of the aspects and factors of websites success. Initially, the traditional approaches of information systems assessment as DeLone and McLean model were extended to websites by proposing some new measures for each construct of the original model (see DeLone and McLean , 2004). Later the websites were viewed as a new phenomena and the problem of assessment of websites was addressed in a new way. The most popular methodology for website evaluation was proposed by Alexander and Tate who defined five main criteria: accuracy, authority, objectivity, currency and coverage of web sites (Alexander and Tate, 1998). The Web site quality evaluation method (QEM) developed by Olsina uses the hierarchical system of attributes to assess the quality of academic Web sites (Olsina et al., 1999). Selz and Schubert used a specific Web assessment model to identify and evaluate successful commercial applications (Selz and Schubert,1997). There are many specific methodologies addressing assessment of websites from different domains - e-commerce, e-health, e-government, e-learning, etc.

The studies in information systems area are generally conceptual studies, providing a research infrastructure and discussing which measures are more important than the others. However, these measures are usually not applied to assess websites, as informing systems, with their specific features.

\section{Websites Assessment Framework}

Our goal is to assess the quality of websites from the perspective of how they inform their users, to investigate the "informativeness" of the system. When applying usability to Web applications, some adjustments and refinements to general definitions are needed to capture the specific usage of websites as informing media. Paraphrasing the ISO definition, Web usability can be considered as the ability of Web applications to support users' tasks with effectiveness, efficiency and satisfaction.

The main aspects of usability in examining the websites are:

$>$ effectiveness - the degree of correspondence between the website functionality and users needs, goals and search and navigation skills;

$>$ efficiency - a quantification of the amount of useful activities through users' interactive browsing behaviour;

$>$ user satisfaction - subjective emotional and aesthetical user estimation about the interaction with the website.

The above criteria are applied to websites' properties considering their quality as an informing system (Figure 1).

These criteria and relationships between them are examined through predefined measures divided into three groups: measures for quality of retrieved information, technology-oriented measures, user-oriented measures. 


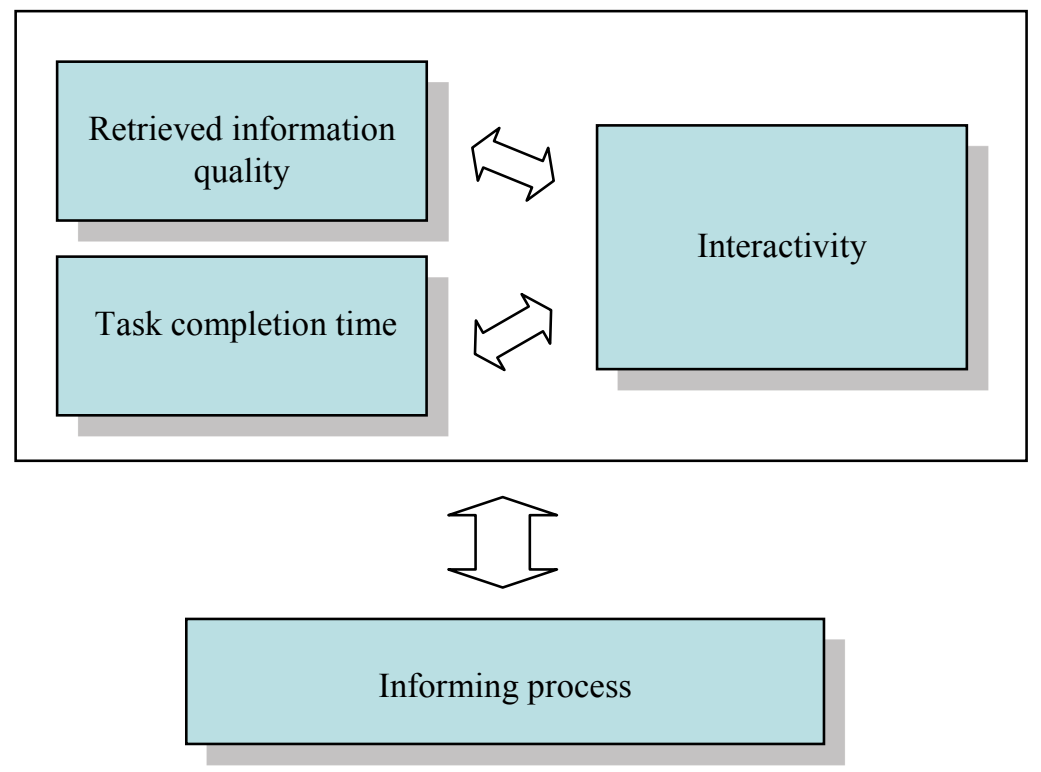

Figure 1 Website evaluation framework

\section{Matrix model}

The model is based on the three fundamental criteria:

\section{Effectiveness}

In the methodology we have presented, the evaluation of website effectiveness is focused on the quality of information retrieval process and the ability of the website to inform users effectively on solving their tasks. The stress is on the content available via the website. The good layout and design can help to increase the number of visitors, but the decisive factor is the usefulness of the presented information. It has to be well-defined, detailed, unique, actual, and trustworthy. Sometimes websites contain heterogeneous data from various subject areas. Therefore a website has to provide the users with well-organized and logically structured information with appropriate navigation through the website sections.

Effectiveness is related to the provision of relevant information, delivered in a timely and usable manner to allow users to obtain rational and informed decisions. It is evaluated based on the level of performance for a specific task.

The evaluation of website effectiveness is based on relevant characteristics of user-system interaction. The problem is related to the fact that users do not use the whole range of services that the system provides and / or tasks that can be solved with the system. There are two reasons for that: firstly, because they do not need all of them or, secondly, because they do not know how to use them. In most cases there is a discrepancy between the functional scope of the system and its usefulness from the user's perspective.

In evaluation of effectiveness answers to the following questions must be considered:

$>$ Does the website cover the topic comprehensively in appropriate style for the audience? Do the level and the depth of the information meet users' needs?

$>$ Is the information laid out clearly, well defined, understandable? 
$>$ Is the information logically structured with well-organized subsections, to provide visitors with an intuitive sense of orientation? Is there a way to search the site itself if a user can't find what she or he is looking for?

$>$ Is a proper navigation provided within the website? Can the user easily navigate from one part of the site to another? Are links clear, meaningful and properly named? Are the links up-to-date and working?

$>$ Is there a clear indication when the information was published and/or "last updated'? Is the information up-to-date? How frequently is the website updated?

$>$ Is this valid information? What evidence is there that information is accurate and credible? Is the author identified? Is the author affiliated to a credible organization? Is information trustworthy?

$>$ Does the site provide any feedback possibilities? Does the site include contact information with the author/designer?

Consequently the main attributes of effectiveness are as follows: content, information structure and organization, validity and credibility of information, navigation, feedback.

\section{Efficiency}

Measures of efficiency are usually used to estimate the factors, which are in direct relationships with the system technology. Most of them are quantifiable, like database coverage and volume, the response time for the search process, etc. However, sometimes it is very difficult or even impossible to evaluate resources spent on task such as labour hours, data processing, cost and materials consumed and to detect the role of the feedback.

Web applications efficiency means that users who want to find some contents can reach them quickly through navigating via available links. Sometimes it is called navigation efficiency. Indicators of efficiency are task completion time and learning time. In this study, we use task completion time as the primary indicator of efficiency. Evaluated average task completion time has to be measured and used in comparison with similar systems, used by the same group of users for solving the same tasks. The group of users must have work in similar conditions, regarding equipment, physical and organizational environments and other aspects that may influence the interaction.

\section{User Satisfaction}

User satisfaction is an ambiguous and abstract concept. The actual manifestation of the state of satisfaction varies from person to person. It depends on website performance and website effectiveness as well as user's experience. Satisfaction is a subconscious affective reactions relating to moods, feelings or attitudes. It captured both psychological and physical aspects of user's attitude toward the website. User satisfaction is defined therefore as the degree of correspondence between the personal expectation a customer has about the website and the actual achievement perceived.

Therefore user satisfaction is an overall evaluation of website functions and features highly depending on context and the specific task assigned. Besides, the website efficiency (task completion time) and effectiveness (task completion rate), the answers to the following questions define the concept of user satisfaction evaluation:

$>$ Is information easy to find, read and use? Can the user easily get to the information they're looking for? Are the materials worthwhile and valuable? 
$>$ Does the website functionality correspond to a regular user's IT knowledge and skills?

$>$ Does the website have an appropriate and pleasant design and user interface?

$>$ Does the website meet the users' notions and expectations?

User satisfaction is based on the general impression and attitude toward the website. Four factors of user satisfaction, relevant to website design, have been selected: easiness of use, learnability, aesthetics and enjoyment.

Relationships between three main criteria and three groups of measures are presented in a constructed matrix model of proposed methodology (Table 1).

\begin{tabular}{|l|l|l|l|}
\hline \multicolumn{5}{|c|}{ Table 1: The matrix model } \\
\hline MEASURES & $\begin{array}{c}\text { MEASURES FOR } \\
\text { QUALITY OF } \\
\text { RETRIEVED } \\
\text { INFORMATION }\end{array}$ & $\begin{array}{c}\text { TECHNOLOGY- } \\
\text { ORIENTED } \\
\text { MEASURES }\end{array}$ & $\begin{array}{c}\text { USER-ORIENTED } \\
\text { MEASURES }\end{array}$ \\
\hline EFFECTIVENESS & $\begin{array}{l}\text { Content } \\
\text { Information structure } \\
\text { and organization } \\
\text { Validity and credibility } \\
\text { of information }\end{array}$ & $\begin{array}{l}\text { Navigation } \\
\text { Feedback }\end{array}$ & $\begin{array}{l}\text { Task completion time } \\
\text { (including learning } \\
\text { time). }\end{array}$ \\
\hline EFFICIENCY & Task completion rate & $\begin{array}{l}\text { Task completion } \\
\text { quickly }\end{array}$ & $\begin{array}{l}\text { Learnability } \\
\text { Ease of use } \\
\text { Aesthetics } \\
\text { Enjoyment. }\end{array}$ \\
\hline SATISFACTION & & & \\
\hline
\end{tabular}

This matrix model allows comprehensive assessment of different aspects of websites via analysis of their ability to inform users. This model allows considering websites from point of view of information decision aided systems. Finally, this model overcomes the limits of assuming independence between different criteria and allows the exploration of overlapping.

The aim of the next section is to share the results of an empirical experiment, including data gathering and testing of the proposed methodology. It was used to validate the model, its elements and to test the applicability of the assessment framework. This requires creating domain-specific questionnaires and a set of tasks assigned to be applied by the users.

\section{Empirical Evaluation of Informing Systems}

\section{Experiment Design}

An experiment, designed to verify applicability of the above framework, methodology and assessment model, was performed. The experiment addressed assessment of university websites to inform potential applicants of different educational options. To apply the measures, described 
above, a questionnaire was designed to be filled by users, who were given an assignment to collect information and make an informed decision regarding particular options offered by investigated universities.

The survey collected data for users' opinions regarding university web sites in respect to their quality to inform in decision making. The questionnaire uses the 5-point Likert scale (1: strongly disagree, 5: strongly agree) and higher values show success/satisfaction regarding specific statements. The questionnaire and the set of tasks are given in the appendix.

Some details about the context of the experiment are:

\section{Users}

As a representative part of the population of Internet users have been used students from SULSIT (State University of Library Studies and Information Technologies, Sofia). They are in their first year of bachelor degree in Information Technology and the typical age range is $19-21$. We have 100 respondents very close to the period when they made the decision regarding application for studying in a university. This makes the group of respondents very close to the users who actually need to solve the task of being informed regarding the educational options provided by different universities.

\section{Tasks}

This assignment was a practical component of the course Processes and Models for Informing in SULSIT, Sofia (see Christozov, Denchev, Toleva-Stoimenova, 2009). Students were asked to research information available via the university website in a way to solve a practical task and later to fill the questionnaire regarding their experience during the research process.

It is assumed that the respondents have been looking for a university to study. Actually they did this in the previous year. Choosing a university is based on collecting typical information about it. One way to do it today is the university's website. In this assignment every student was given two universities with two majors for evaluation and comparison. The majors are similar to some extent to the major they are studying at SULSIT in fields closely related to Information Technology.

The students have to collect the following information for those universities from their websites:

$>$ curriculum of a bachelor program;

$>$ additional conditions, including course assignments and projects, internships;

$>$ conditions for degree completion - examinations, thesis.

Websites of five universities assessed in this experiment were: Sofia University (SU), http://www.uni-sofia.bg; Plovdiv University (PU), www.uni-plovdiv.bg; Rousse University (RU), www.ru.acad.bg; Technical University (TU), www.tu-sofia.bg; New Bulgarian University (NBU), www.nbu.bg.

\section{Organizational and technical environment}

Students are familiar with information technologies and have a good computer and Internet literacy. They are provided the requisite equipment for solving this task, such as computer and Internet in a University computer lab. This was done to avoid the bias based on use of different equipment.

The first two questions represent a user's expertise self-assessment. As it is shown below on Fig. 2 students have good computer skills and comfort in using Internet technology. 
Each item on a questionnaire is a measure for a website's informing quality. The answer indicates how much a person agrees or disagrees with the statement.

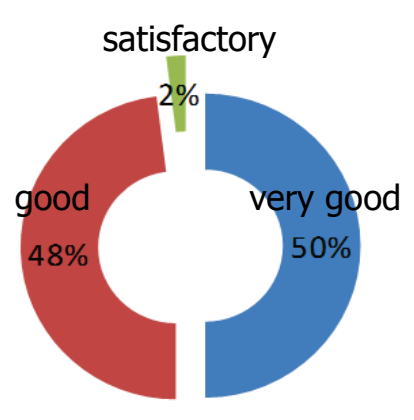

(a)

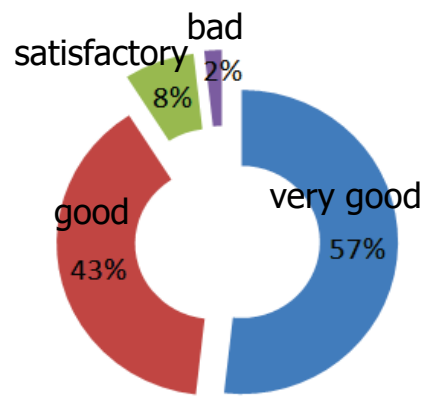

(b)

Figure 2. The respondent's self-assessment of computer (a) and Internet (b) literacy

There are some limitations of this study. The questionnaire does not include credibility issues. When using the Internet as a research tool, the user must differentiate between quality information and misinformation. In this case criteria to be considered include university's reputation, whether the university/specialty is accredited or not and the current students' experience. This credibility verification is not necessary because the investigated websites belong to prestigious universities in Bulgaria with a long-established reputation. There is no doubt about the authorship of the published materials. Besides, websites are not considered as educational websites, but as sources of administrative information (similar to public administration websites).

Another limitation of this study is that the group of respondents is homogeneous. They are students from SULSIT. They worked under direct supervision and control of an instructor with very specific and carefully designed assignments. This guaranteed that they really do what was expected and allows precise measuring the time they needed to manage to obtain the required information. A weakness of this approach is that some students may possess some preliminary expertise about how to search the websites assigned to them.

The users have to receive information only via university's website to evaluate its features, without using other information sources. That explains the absence of a feedback component.

Other variables were constructed from the following groups of questions. The first six questions measure system effectiveness (q1- q6) and user satisfaction is measured by the questions q7 q10. Task completion time, as the difference between start and end, is used as the efficiency measure.

The five university websites are compared in respect of their usability measured by efficiency, effectiveness and user satisfaction. Table 2 summarizes the experience obtained in the distribution of answers.

The calculated curves of efficiency, effectiveness and user satisfaction have properties of normal distribution, according to both the skewness and kurtosis of data set.

As far as efficiency is concerned, NBU curve is an exception, and more than half of the user estimations are highly concentrated in the curve left side.

Regarding effectiveness of RU and TU websites, there are a lot of estimations concentrated in both sides of the curve. Two user groups can then be distinguished based upon this - low-level 
values and high-level values. These results documented significant variations within groups and are considered as a signal for a lack of homogeneity within the RU and TU user groups.

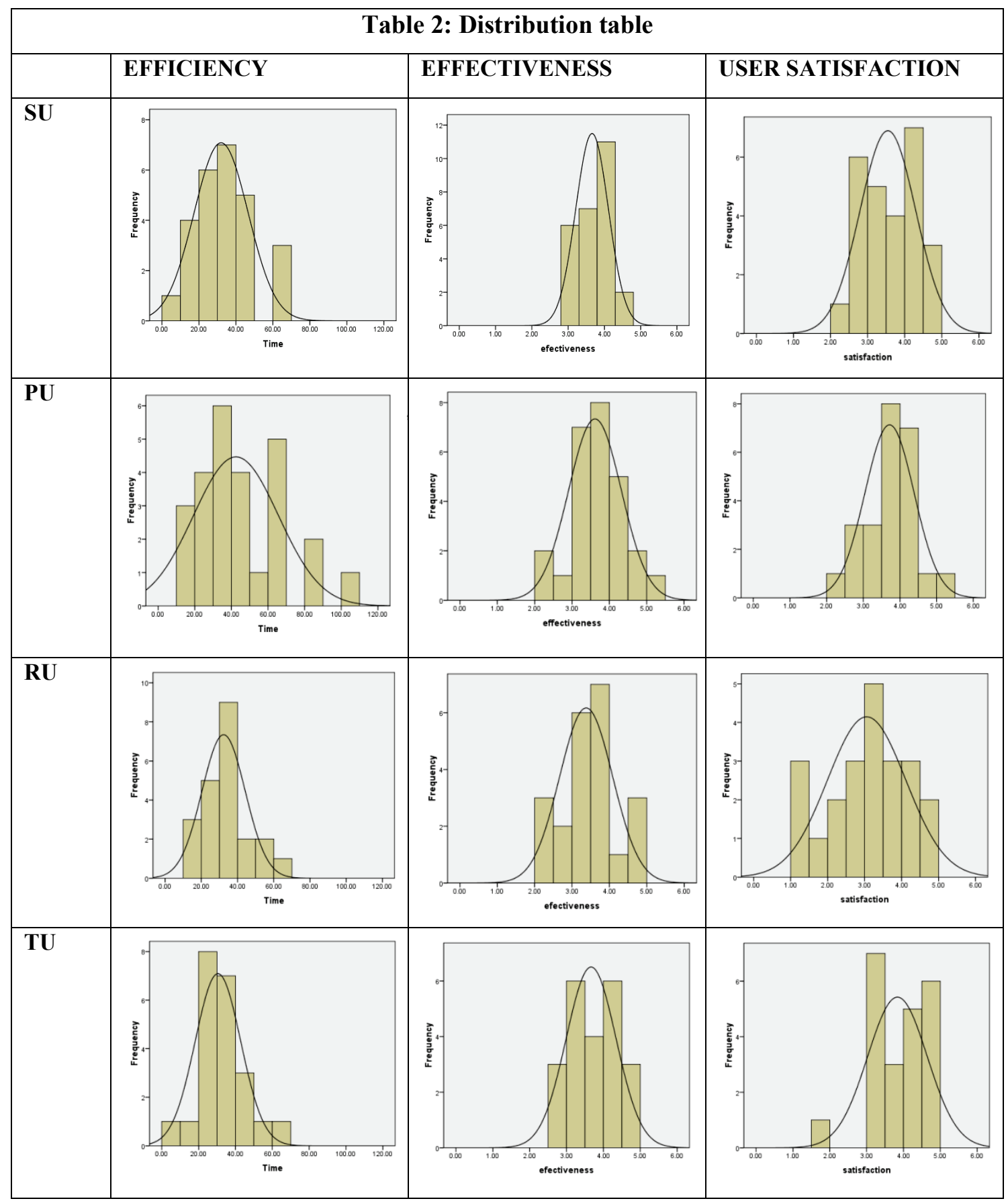




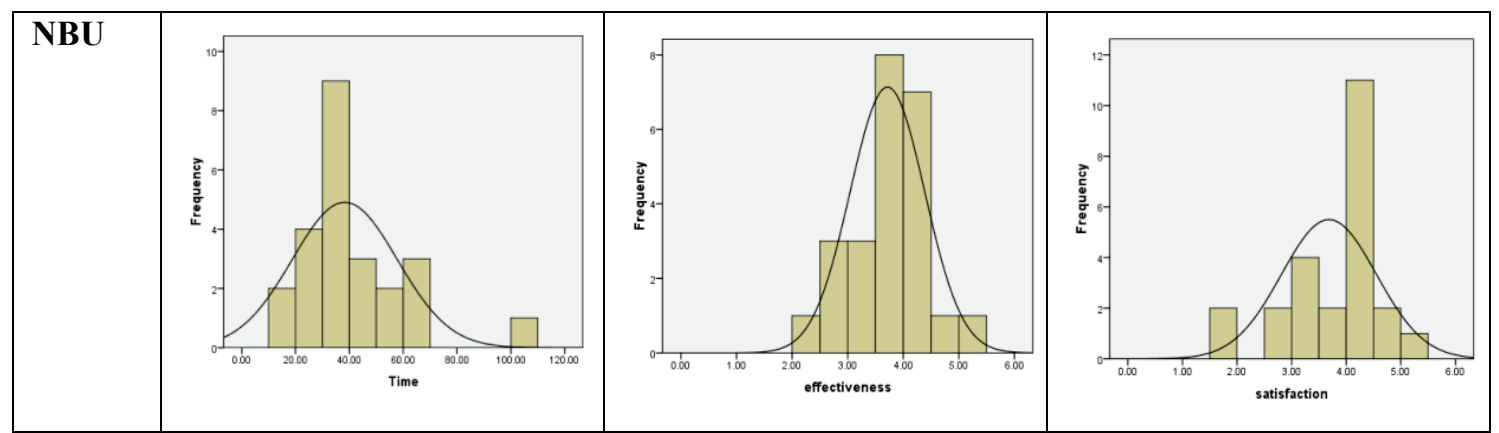

With reference to user satisfaction, the standard deviation regarding RU website is higher compared to the results of other websites. It is also interesting to point out that the comfort level of most of TU and NBU users is very high, while a significant part of PU and RU website users are unsatisfied. We may say that distribution of satisfaction from SU website is close to uniform. The diversity of answers regarding TU website can be interpreted with a statement like "this is not the right way to develop a website to these users". The developing process is a complicated process and depends very much on the audience who is going to use it, which is never the same year by year.

Results obtained show that users rated SU website in the first position as the most "informing" website and placed PU as second with NBU coming closely on the third position. The presence of a significant group of outliers in the results about satisfaction of the other two websites shows a weakness in their design to address a heterogeneous population of users. We may observe a significant discrepancy in RU users' estimation where the high speed leads to low effectiveness and satisfaction. Obviously, the designers had overestimated efficiency at the expense of effectiveness and satisfaction, but the results can be attributed to the group of users engaged in this task.

The work and results reported herein were based on a homogeneous group of users and specific task about retrieving of curriculum related information and do not cover all of the specific features of university websites.

Besides these methodological considerations an interesting conclusion is that, in general, the websites were considered "good" by the students (all of the questions' means are between 3,014,31 in a 5 point scale). Also, the results obtained correspond to www.webometrics.info of Cybermetrics Lab, Spain that rates SU on the 777 position in the world, NBU - 1816, TU - 2409 and PU -3088 according to their website quality and internet presence.

\section{Conclusion}

This paper extended the discussion of the results of an early study, conducted to construct an assessment methodology and metrics for website success. An empirical experiment in the field of university websites was used to validate the model elements and to test the assessment framework. The results proved the applicability of the framework, model and methodology. However, the use of standard sampling method and the homogeneous structure of the respondents made the obtained results, regarding the usability of the investigated websites, difficult to generalize to a larger population. Since the number of respondents were not high enough and diverse enough, statistical reliability was not the major concern of this study.

As further research, the developed framework could be applied to different domains like e-commerce, e-health or another sector. The research has to capture the differences be- 
tween different domains and as a result to adjust the proposed assessment framework. This would create fixed sector-specific questionnaires to be applied by users.

This methodology can be applied in comparison with other assessment models, which will lead to its further evolution.

Also developing a descriptive assessment framework, including relevant statistical inference tools and data analysis methods, which may allow improving the websites' design, is a natural extension of the current study.

\section{References}

Alexander, J., \& Tate, M. A. (1999). Web wisdom: How to evaluate and create information quality on the web. Mahwah, NJ: Lawrence Erlbaum.

Backhouse, J., Liebenau, J., \& Land, F. (1991). On the discipline of information systems: Conflict in the trenches. Journal of Information Systems, 1, 19-27.

Bailey, J. E., \& Pearson, S.W. (1983). Development of a tool for measuring and analyzing computer user satisfaction. Management Science, 29(5), 530-545.

Bevan, N., \& Macleod, M. (1994).Usability measurement in context. Behaviour and Information Technology, 13, 132-145.

Christozov D., S., Denchev, S., \& Toleva-Stoimenova, S. (2009). Informing processes and models: A core course in IS curriculum. Issues in Informing Science and Information Technology, 6, 143-151. Retrieved from http://iisit.org/Vol6/IISITv6p143-151Christozov624.pdf

DeLone, W. H., \& McLean, E. R. (1992). Information systems success: The quest for the dependent variable. Information Systems Research, 3(1), 60-95.

DeLone, W. H., \& McLean, E. R. (2003). The DeLone and McLean model of information systems success: A ten-year update. Journal of Information Systems, 19(4), 9-30.

DeLone, W. H., \& McLean, E. R. (2004). Measuring e-commerce success: Applying the DeLone and McLean model of information systems success model. International Journal of Electronic Commerce, 9(1), 31-47.

Doll, W., \& Torkzadeh, G. (1988). The measurement of end-user computing satisfaction. MIS Quarterly, $12(2)$.

Doll, W., \& Torkzadeh, G. (1991). The measurement of end-user computing satisfaction: Theoretical and methodological issues. MIS Quarterly, 15(1).

Frøkjær E., M., \& Hertzum, K., (2000). Hornbæk measuring usability: Are effectiveness, efficiency, and satisfaction really correlated? Proceedings of the ACM CHI 2000 Conference on Human Factors in Computing Systems (The Hague,The Netherlands, April 1-6, 2000), p. 345-352. ACM Press, New York. Preprint version.

Gable, G., Darshana S., \& Chan, T. (2003).Enterprise systems success: A measurement model. TwentyFourth International Conference on Information Systems, Dec. 14-17, Seattle, USA.

Ives, B., Olson, M. H., \& Baroudi, J. J. (1983). The measurement of user information satisfaction, Communications of the ACM, 26(10), 785-793.

Jiang, J., Klein, G., \& Carr, C. (2002). Measuring information systems service quality: SERVQUAL from the other side. MIS Quarterly, 26(2), 145-166.

Nielsen, J. (1993). Usability engineering. Boston: Academic Press.

Olsina L., \& Rossi, G. (2002). Measuring web application quality with WebQEM. IEEE Multimedia Magazine, 9(4), 20-29. 
Pitt, L. F., Watson, R. T., \& Kavan, C. B. (1995). Service quality: A measure of information systems effectiveness. MIS Quarterly, 19(2), 173-187.

Sabherwal, R., Jeyaraj, A., \& Chowa, C. (2006). Information system success: Individual and oranisational determinants. Management Science, 52(12), 1849-1864.

Seddon, P. B. (1997). A respecification and extension of the DeLone and McLean model of IS success. Information Systems Research, 8(3), 240-253.

Selz, D., \& Schubert, P. (1998).Web assessment - A model for the evaluation and assessment of successful electronic commerce applications. Proceedings of the 31st HICSS Conference, Hawaii, "Internet and the Digital Economy Track", Vol. IV, pp. 222-231.

Toleva-Stoimenova, S. (2010), Evaluation of web based information systems: Users' informing criteria. Issues in Informing Science and Information Technology, 7, 297-310. Retrieved from http://iisit.org/Vol7/IISITv7p297-309Toleva777.pdf

Zviran, M., Glezer, C., \& Avni, I (2006). User satisfaction from commercial web sites: The effect of design and use. Information Management, 43(2), 157- 178.

\section{Biographies}

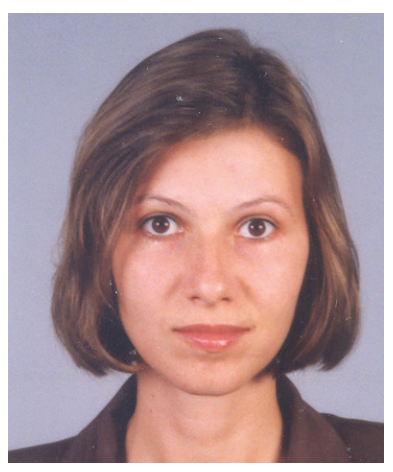

Stefka Toleva-Stoimenova is an Assistant Professor in Computer Science Department at the State University of Library Studies and Information Technologies, Sofia, 119, Tzarigradsko Shosse Blvd. Bulgaria 1784, s_toleva@yahoo.com. She has obtained her MSc degree in Industrial Automation from the Faculty of Automation and System Design, Technical University - Sofia. In 2011 she received a PhD degree from SULSIT in Automated Systems for Information Processing and Management. Her publications and main research interests are in the field of Automation, Informatics and Informing Science.

She is a member of the Bulgarian Informing Science Society.

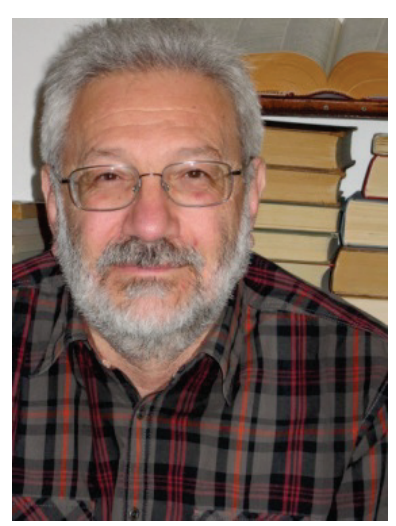

Dimitar Christozov has been a Professor of Computer Science at the American University in Bulgaria. He has more than 30 years of experience in areas as computer science, quality management and information systems. He graduated Mathematics from Sofia University "St. Kliment Ohridski" in 1979. He completed his PhD thesis "Computer Aided Evaluation of Machine Reliability" in 1986. In 2009 he completes his D.Sc. thesis on "Quantitative Measures of Informing Quality". In ICTT "Informa" (1986-1993) Dr. Christozov was involved in establishing the national information network for technology transfer and conducted research in the areas of technologies assessment, integral quality measures and information systems for quality management. In these areas he was recognized as one of the leading experts in Bulgaria. Professor Christozov has more than 80 publications as separate volume, journal papers and papers in refereed proceedings. He is a founding member of Informing Science Institute and chair of Bulgarian Informing Science Society; and founding member of the Bulgarian Statistical Society. 